\title{
Enhancing Production Efficiency of Oil and Natural Gas Pipes Using Microwave Technology
}

\author{
Wissam M. Alobaidi1 ${ }^{*}$, Entidhar A. Alkuam², Eric Sandgren1, Hussain M. Al-Rizzo1 \\ ${ }^{1}$ Systems Engineering Department, Donaghey College of Engineering \& Information Technology, University of \\ Arkansas at Little Rock, Little Rock, Arkansas, USA \\ ${ }^{2}$ Department of Physics and Astronomy, College of Arts, Letters, and Sciences, University of Arkansas at Little \\ Rock, Little Rock, Arkansas, USA \\ Email: *wmalobaidi@ualr.edu
}

Received 6 July 2015; accepted 7 September 2015; published 10 September 2015

Copyright (C) 2015 by authors and Scientific Research Publishing Inc.

This work is licensed under the Creative Commons Attribution International License (CC BY).

http://creativecommons.org/licenses/by/4.0/

(c) (7) Open Access

\section{Abstract}

The research reported in this paper aims at developing means of Non Destructive testing (NDT) to increase the line efficiency of pipe production in oil and natural gas pipe manufacturing plants using the Standard Allowed Minutes (SAM) method. Existing line production stations encounter difficulties in maintaining the recommended testing speed of smaller diameter pipe, due to limitations in the Visual Inspection (VI) station. We propose to implement one additional technique which will prevent the decline of line efficiency in a pipe production factory. The range of diameters identified as a problem in this research is from $254 \mathrm{~mm}$ to $762 \mathrm{~mm}$. Microwave techniques are expected to improve the line efficiency by increasing the production of the plant. This happens as a consequence of maintaining the production rates of the identified pipe diameters, so that they equal the production output of the larger pipe diameters. We analyze the velocity traveled by the pipe through Radiographic Testing (RT) according to the VI output (production). The RT velocity is decreased for the diameters identified above, in order to maintain quality control and cover the shortcoming of the VI. The number of pipes produced is computed during shift hours of the factory and pipe lengths of the forming department are determined. We compare the output (production) of a series of NDT line stations with and without the microwave technique for the first of the three pipe cases considered in this study, classified as perfect pipe (PP), repair pipe (RP) and scrap pipe (SP). The velocity of RT stations analyzed in the paper ranges from $50 \mathrm{~mm} / \mathrm{s}$ for larger diameter pipe, and decline to $16.667 \mathrm{~mm} / \mathrm{s}$ for the identified diameters. The analytical calculations of line output (production) and line efficiency demonstrate the solution of this velocity problem after the microwave technique is introduced. It demonstrates that an economical and precise methodology to extend the production capability of the pipe plant has been determined.

${ }^{*}$ Corresponding author.

How to cite this paper: Alobaidi, W.M., Alkuam, E.A., Sandgren, E. and Al-Rizzo, H.M. (2015) Enhancing Production Efficiency of Oil and Natural Gas Pipes Using Microwave Technology. Energy and Power Engineering, 7, 440-450.

http://dx.doi.org/10.4236/epe.2015.710043 


\section{Keywords}

\section{Microwave Technology, Non Destructive Testing (NDT), Spiral Pipe Process (SPP), Pipe Inspection, Standard Allowed Minutes (SAM)}

\section{Introduction}

Oil pipes with diameters up to $500 \mathrm{~mm}$ are used as the standard method of transporting petroleum and derivatives or natural gas for great distances overland. Corrosion of the inner pipe wall often occurs at the bottom of the pipe in the field because of the presence of water in the pipelines [1]. This corrosion leads to removal of material, creating a reduction in the wall of the pipe, called Pipe Wall Reduction (PWR) [2] [3]. Defects develop even during the manufacturing process, but these are often caught in factory due to standard testing guidelines. Such discontinuities can be assessed and repaired per the standards and codes, before the pipe is shipped to the field. During its time in service, any pipeline will develop discontinuities that are of a greater extent than those show up in manufacturing. Once again, there are standards that can be used to determine whether repair or replacement is the proper action on a case by case basis [4] [5].

Seeking a solution for determination of whether a field-defective pipeline is still suitable for service has inspired a great deal of research. A number of analytical approaches have been tested for detection and sizing of such defects in situ [6].

NDT techniques have been developed during the past few decades to determine the presence and extent of such discontinuities. Our previous survey paper reviewing the application of several of these NDT methods looked at digital X-ray, ultrasonic, visual inspection, radiographic testing and so on [5]. Detection of surface defects requires a large amount of time and labor for each of these techniques. For larger diameter pipes the techniques can be used effectively, but smaller diameter pipelines prevent entry of human inspectors to perform visual inspection, for example [5].

Previous studies have demonstrated that microwave NDT techniques can reliably detect surface defects in pipes. The technique uses a microwave emitter/detector that introduces a microwave signal into the waveguide (the pipe itself) and detects the reflected waves [3] [7]. Normal pipe walls generate a constant resonant frequency (no loss in energy) in the reflected waves. PWR creates variances in the waveforms produced, allowing calculation of the location and extent of PWR defects. Inspecting the pipe inner walls can be done without entering the pipe, and without moving the detector during the test, while detection proceeds in real time. This has obvious advantages in the case of smaller diameter pipeline [3].

After the advantages of microwave NDT techniques become widely known, we foresee the inclusion of microwave testing stations among the series of NDT testing stations in pipe manufacturing facilities.

Standard Allowed Minutes (SAM) was used to establish a general plan for the target (line output and line efficiency standard) and was developed by analysis of the time required to produce the product [8] [9].

Many of the techniques listed in our survey paper work are well with larger diameter pipes, but are difficult or impossible to use on smaller diameter pipes [5].

We present an analytical study of inspection routines including Visual Inspection (VI) and Radiographic Testing (RT) with and without the microwave technique (which will be placed between VI and RT) for smaller diameter pipe, and then study the case of the PP with the SAM for the two routines.

It is worth mentioning that this paper essentially aims to enhance the production and line efficiency of oil and gas pipes by using microwave technology. The observational study employs microwave technology to carry out the testing of the inner surface of the pipe to meet the VI requirement. The commonly used VI station can carry out the test for all diameters except the group ranging in size from $254 \mathrm{~mm}$ to $762 \mathrm{~mm}$, which cannot be inspected from the inside with VI.

This limitation requires slowing the velocity of the test pipe in the RT station, as mentioned in our previous study, from $50 \mathrm{~mm} / \mathrm{s}$ to $16.667 \mathrm{~mm} / \mathrm{s}$ [5]. Placing microwave technology between the two stations has three advantages. First, the velocity of the RT station up to the customer requirement is got. Second, to inspect the pipe from inside for those smaller diameters listed above. Consequently, the pipe can be released to the RT station without interruption, resulting in improved line efficiency and line output of the product. Third, the high quality 
of the product during the test is ensured.

This research will confirm the times needed for examination of the pipe after its formation for the diameter range listed above. Then we will compute the line production values to yield line efficiency for each station, by analyzing the necessary decrease in speed of the wagon that carries the pipe to conduct the ultrasonic test for the weld before the radiography test. Calculations will be performed for various lengths of pipe: 24,384 mm, 21,336 $\mathrm{mm}, 18,288 \mathrm{~mm}$ and 15,240 $\mathrm{mm}$ respectively. Line production and line efficiency will be computed for various shift lengths: 8 hrs, 9 hrs, 10 hrs, 11 hrs and 12 hrs. After adding microwave technology the computations will be repeated for the new setup. Results for the previous sequencing of stations after VI will be compared to the new sequence including the microwave technique which evaluates the pipe from inside.

\section{Sequential Stations of Non-Destructive Examination in Spiral Pipe Plants}

- Coil Ultrasonic Testing (COIL UT): This station is responsible for detecting discontinuities in the materials of the pipe body before it is spirally formed. The station uses straight beam ultrasonic signals to test the roll stock, as shown in Figure 1. COIL UT allows identification of discontinuities with enough precision to allow the ones that exceed the standards to be cut away before the pipe is formed. In most cases the manufacturer specifications require a clean run of at least 40 feet up to 80 feet, for the roll stock to be usable [10] [11].

- Visual Inspection (VI): After the formation of the pipe and the application of spiral welds internally and externally, the pipe is sent to the VI station to evaluate the pipe body and its welds for outer diameter (OD) and inner diameter (ID) [5] [12].

- Radiography Testing (RT): Inspection in this station is confined to the spiral weld only, from the front end to the tail end of the pipe. This station contains two examination methods, as shown in Figure 1. First is the Ultrasonic machine to give an indication of the manpower needed. The examination process follows the weld by spiral rotational movement of the pipe, to ensure the probe is placed reliably to provide indication of any discontinuity for the ID and OD (two separate groups of probes are used to test the ID and OD of the weld simultaneously). The second is the RT machine which is used when UT indicates that follow-up inspection is necessary [5] [13].

- Hydraulic System (HS): This is a system to inject water inside the pipe to create the amount of internal pressure called for by the requirements and standards code. Pipes are checked for any leakage [14].

- Seam Ultrasonic Testing (SEAM UT): This machine is limited to the main section of the weld. Probes are used to test the ID and OD of the weld, beginning $200 \mathrm{~mm}$ from the front end, and ending at $200 \mathrm{~mm}$ from

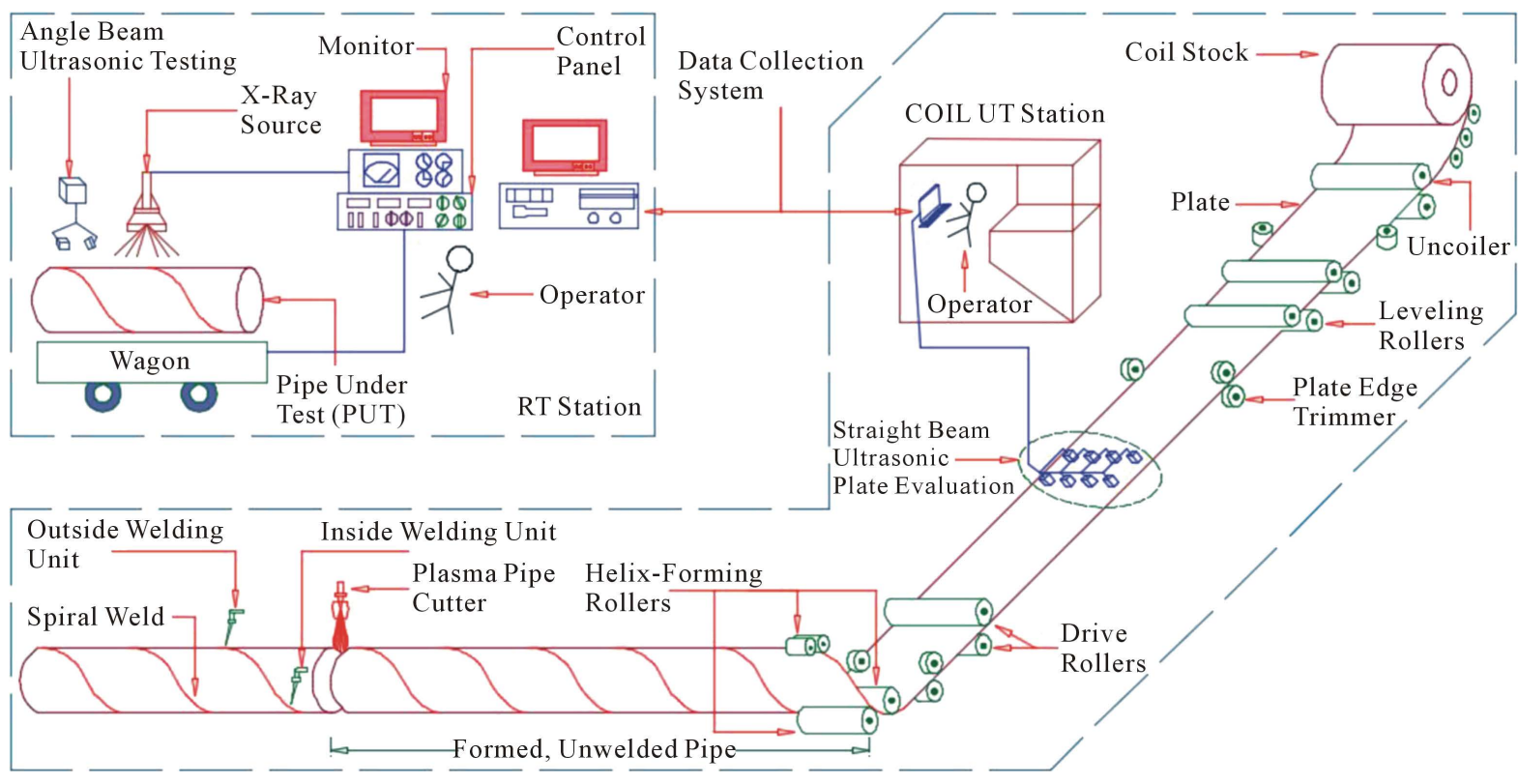

Figure 1. Illustration of oil and natural gas pipe manufacturing process. 
the tail end (to protect the probes from damage due to contact with the flanges of the pipe). The pipe is moved helically for scanning. This test paints a red line on any section of the weld that shows a discontinuity. The red lines indicate to the NDT person which areas must be tested at the next station [11] [15].

- Manual Ultrasonic Testing (MUT): This testing station includes two checks of the pipe. First is the straight beam probe. This is used to check the body of the pipe circumferentially from the outside within a $254 \mathrm{~mm}$ linear distance from both front end and tail end (to cover the pipe body in the areas not covered by SEAM UT). Second is the angle beam probe. This checks the spiral weld at both front end and tail end, within a 254 $\mathrm{mm}$ linear distance. The angle beam probe is then used to check any indication from the SEAM UT (red painted areas) of a discontinuity along the spiral weld [11] [16].

- Digital X-Ray (D-XR): This last station is for verifying the places that have been pointed out by MUT. After this test, pipes with defects needing repair (RP) are sent to the repair station. Scrap pipe (SP) go to the scrap area. Perfect pipe (PP) goes to the beveling station, then to final inspection [5] [17].

- Microwave Inspection: High-frequency Weld (HFW) or Electrical Resistance Weld (ERW) small diameter steel pipe is sometimes tested with microwave signals. This kind of pipe is useful in situations with liquids under reduced pressure, such as the transfer of water, oil, and in equipment manufacturing [18] [19]. All of the research done on microwave as an NDT technique was done with smooth inner wall pipe of this type [3] [7]. We propose to incorporate the microwave technique to test spiral weld pipe to reduce the test times spent in the stations following visual inspection (where the pipe cannot be entered by manpower for direct visual inspection, due to small inner diameter). Figure 2 shows the schematic of the microwave process.

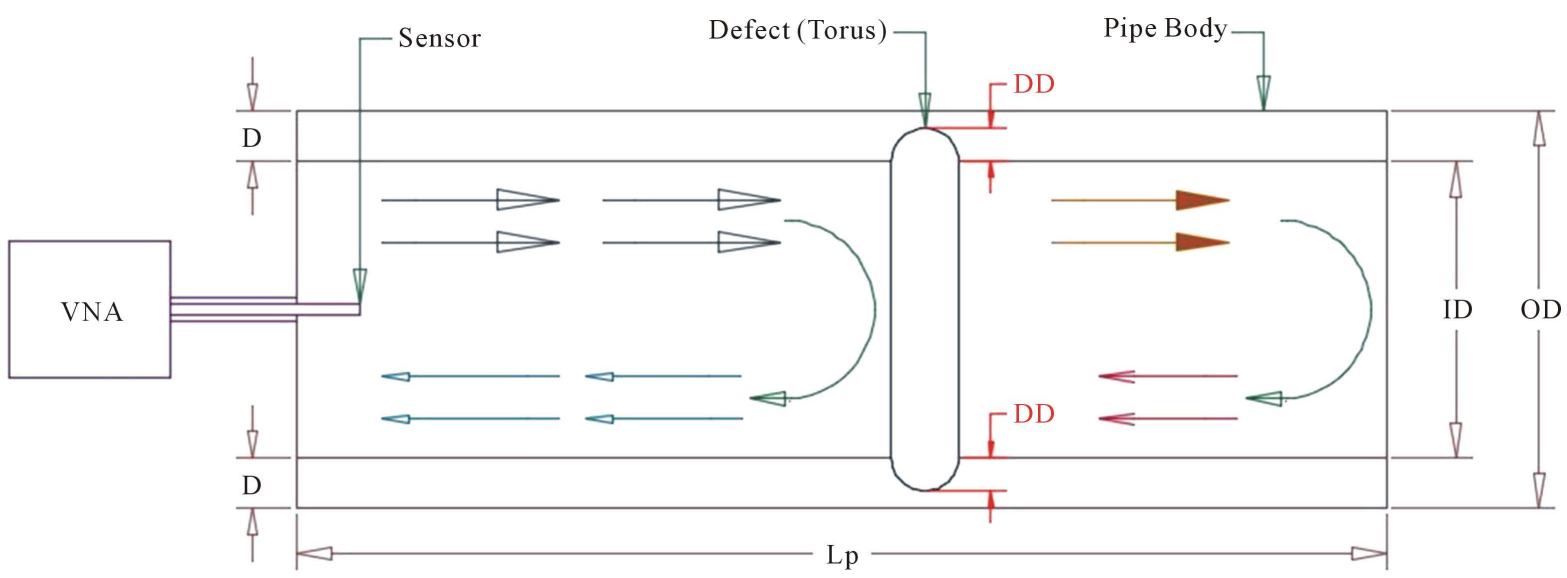

Figure 2. Illustration of a typical setup for microwave propagation for NDT of small diameter pipe. VNA is a vector network analyzer, $\mathrm{L}_{\mathrm{p}}$ is the length of the pipe, $\mathrm{D}$ is the material thickness and DD is depth of the defect.

\section{Theoretical Analysis}

\subsection{Confirming the Time Inspection of the VI and RT Stations for PP Case}

In manufacturing plants is always considered the perfect product for setting up the output line charts daily, weekly and monthly [20]. To customize the standard timing, when pipes containing defects are found, the material is divided into three cases: Perfect Product (PP), Repair Product (RP) and Scrap Product (SP). Furthermore, the correct timing of the product is always based on the product free of defects. This concept is extensively used in various industries [5]. As shown in Figure 3, the path overview of the series of NDT stations for evaluating pipes in manufacturing and testing commences with visual inspection and ends at the production area. For this evaluation, we apply the concept of SAM to pipe manufacturing [21] [22]. It is worth mentioning that, while the time the PP spends in the NDT area is not exactly a SAM, it is considered as an exact time to conduct the partial test and full test as shown in Figure 4, in order to inspect the pipe in the VI station. The pipes are split into two groups based on diameter: the first group (G1) consists of pipes ranging from 254 to $762 \mathrm{~mm}$ in diameter, and the second group (G2) ranging from $889 \mathrm{~mm}$ to $1270 \mathrm{~mm}$ in diameter. Generally, these two groups will control the increase and decrease in the line output for each station. Thereby, line efficiency (LE) is different for G1 and G2. 


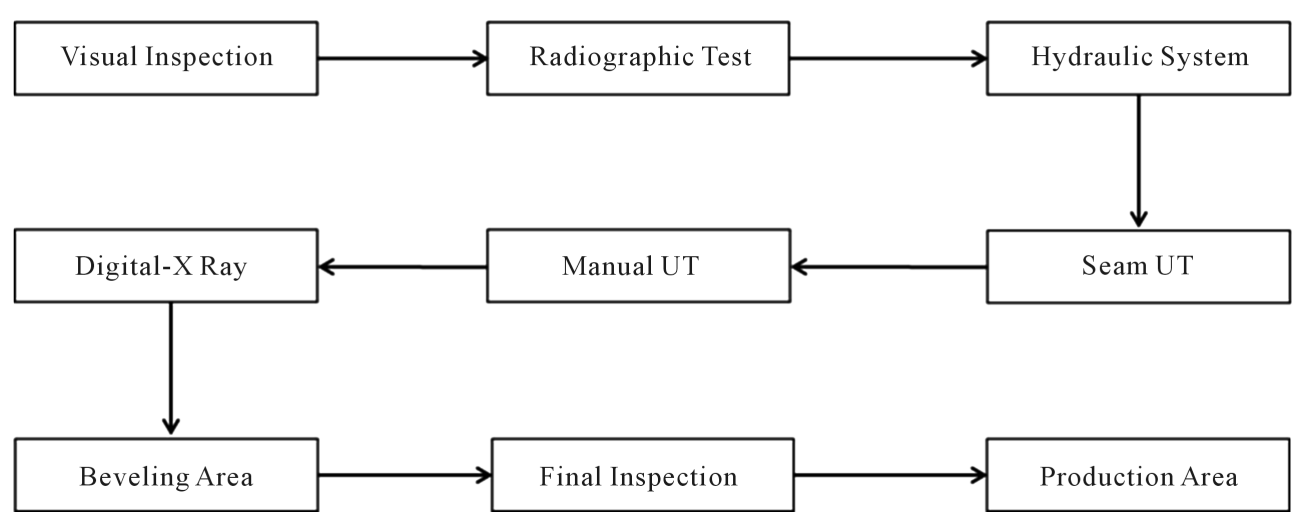

Figure 3. Path overview of NDT stations, used in the evaluation.

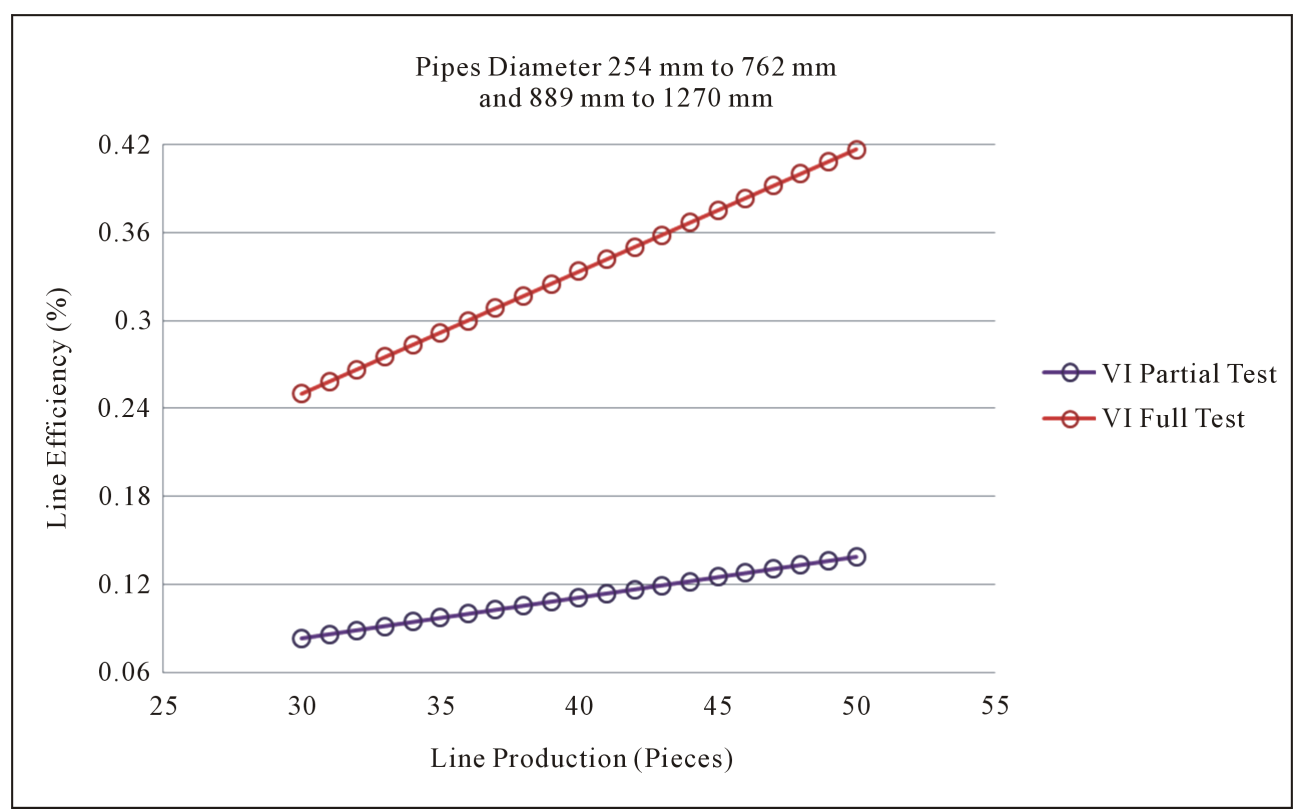

Figure 4. Evaluated times for VI station as per the G1 \& G2, with pipe length 24,384 mm, number of operator 3 and shift work 8 hrs.

The three equations below are excerpted from [21].

$$
\text { Line Efficiency }=\frac{\text { Total Minutes Produced }(\mathrm{TMP})}{\text { Total Minutes Attended }(\mathrm{TMA})} \%
$$

Exact time to inspect outside diameter $(\mathrm{ETOD})=4 \mathrm{~min}$, as well as exact time to inspect inside diameter $(E T I D)=11 \mathrm{~min}$. This term is total exact time $($ TET) $=15 \mathrm{~min}$ for each pipe. Moreover, the line output (LO) of this station ranges from 30 to 50 pieces/shift, per the working conditions for the shift period of 8 hrs. So, G1 matches to the ETOD and G2 to the TET.

$$
\mathrm{TMP}=\mathrm{LO} * \mathrm{TET}
$$

Because of the difficulty the operator has in testing and going through the G1 pipes from the inside. At this point only the process called partial test is appropriate for G1. Therefore, the full test relates to G2, because of the ease of inspecting the pipe from the inside as well as outside. Once the full and partial testing modes of the VI station for PP are quantified, in accordance to what has been mentioned above, the time for the full test is set up to be higher than that for the partial test for pipe length $24,384 \mathrm{~mm}$.

Further, the LEF depends on the TMP, and is changed through Equation (1), depending on the constancy of TMA, which is described below. 


$$
\mathrm{TMA}=\mathrm{NOP} * \mathrm{WH} * 60
$$

where NOP is number of operators and WH is working hours, both per shift.

Inspection time of the PP through the VI station will decrease because only the VI partial test is done on the product (G1) to insure the quality of the weld only, not for the body; but the partial VI test increases the time spent in RT. The PP case of various length and diameters of pipe in G2 were successfully inspected and evaluated at the recommended velocity of $50 \mathrm{~mm} / \mathrm{s}$ when the RT station comes after the VI station [5]. Whereas, in the case of PP from G1, VI followed by microwave technique (MWT) could be used to decrease the inspection time in the RT station.

The velocity of the wagon utilized to move pipe through the testing stations controls the time spent in each station. The TET is relative to the length of the pipe. For PP we get the minimum test processing (time interval) for any station. The velocity can be mathematically computed through displacement function to the velocity and PP time interval. Descending velocity occurs for G1 as shown in Figure 5, which leads to increased time interval. The velocities of the G1 PP inspection decrease, because quality control for the pipe weld can then be given as the indication for decreasing the $\mathrm{LO}$ and LE.

When using G1 to calibrate the RT wagon velocity, the recommended velocity decreases as demonstrated in Figure 6, for different proposed shift periods and different pipe lengths.

\subsection{Time and Speed Analysis for Inspect PP with in VI, MW and RT}

The microwave (MW) station has been proposed to work with G1 pipe. It is expected that the MW station located after VI will increase both the LO and the LE of the PP to be inspected by the RT station. With the MW station working, the partial test for a PP in Figure 4 is not needed. As shown in Figure 7, PP ranging from 30 to 50 pieces for each station (VI, MWT \& RT) per shift were suggested for different cases as a LO, and improvements in the LE were obtained automatically. The TETs in the MW station are $2.5 \mathrm{~min}, 3 \mathrm{~min}, 3.5 \mathrm{~min}$ and 4 min with the tests applicable to the PP lengths $15,240 \mathrm{~mm}, 18,288 \mathrm{~mm}, 21,336 \mathrm{~mm}$ and 24,384 mm respectively. These lengths were evaluated with MWT and each length was run with different shift hours in order to analyze the MWT efficiency at the recommended velocity $(50 \mathrm{~mm} / \mathrm{s})$ for the RT station.

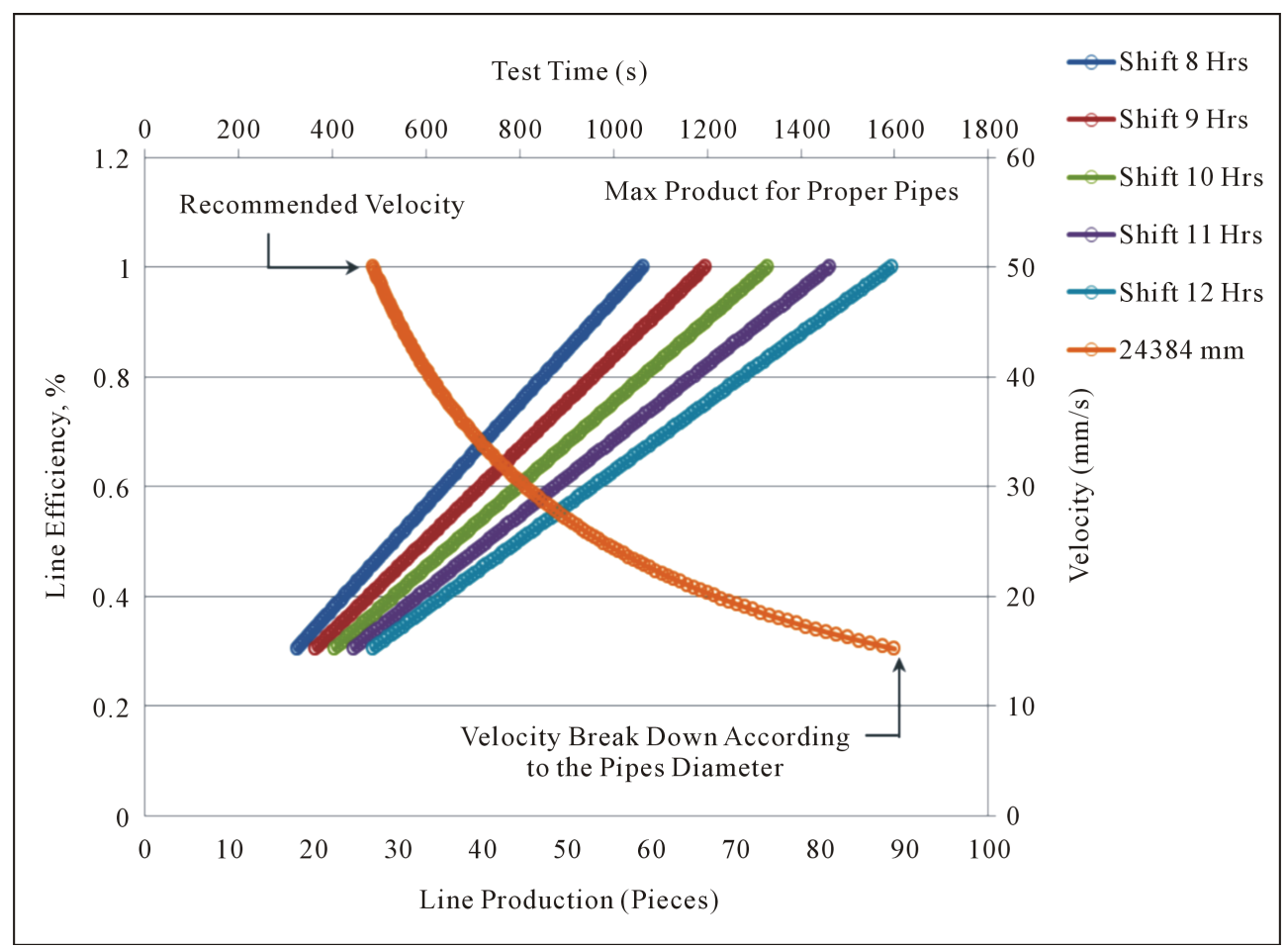

Figure 5. Inspection times for RT station as per the G1, with long pipe $24,384 \mathrm{~mm}$, NOP = 1 and various shift hours. 


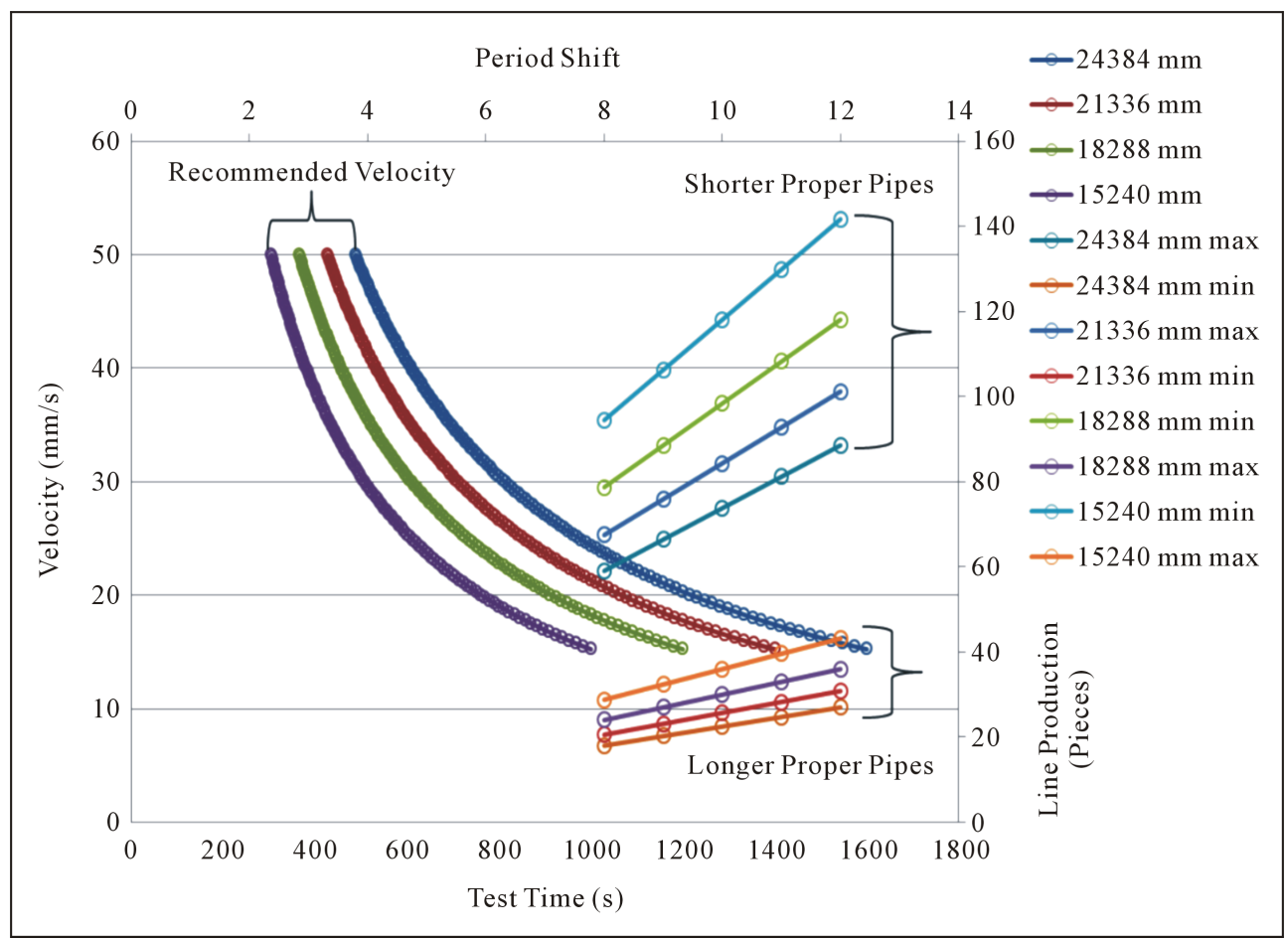

Figure 6. Calibrate velocity as per the G1, with long pipes 15,240 mm, 18,288 mm, 21,336 mm and 24,384 mm, NOP = 1 and different period shift hours.

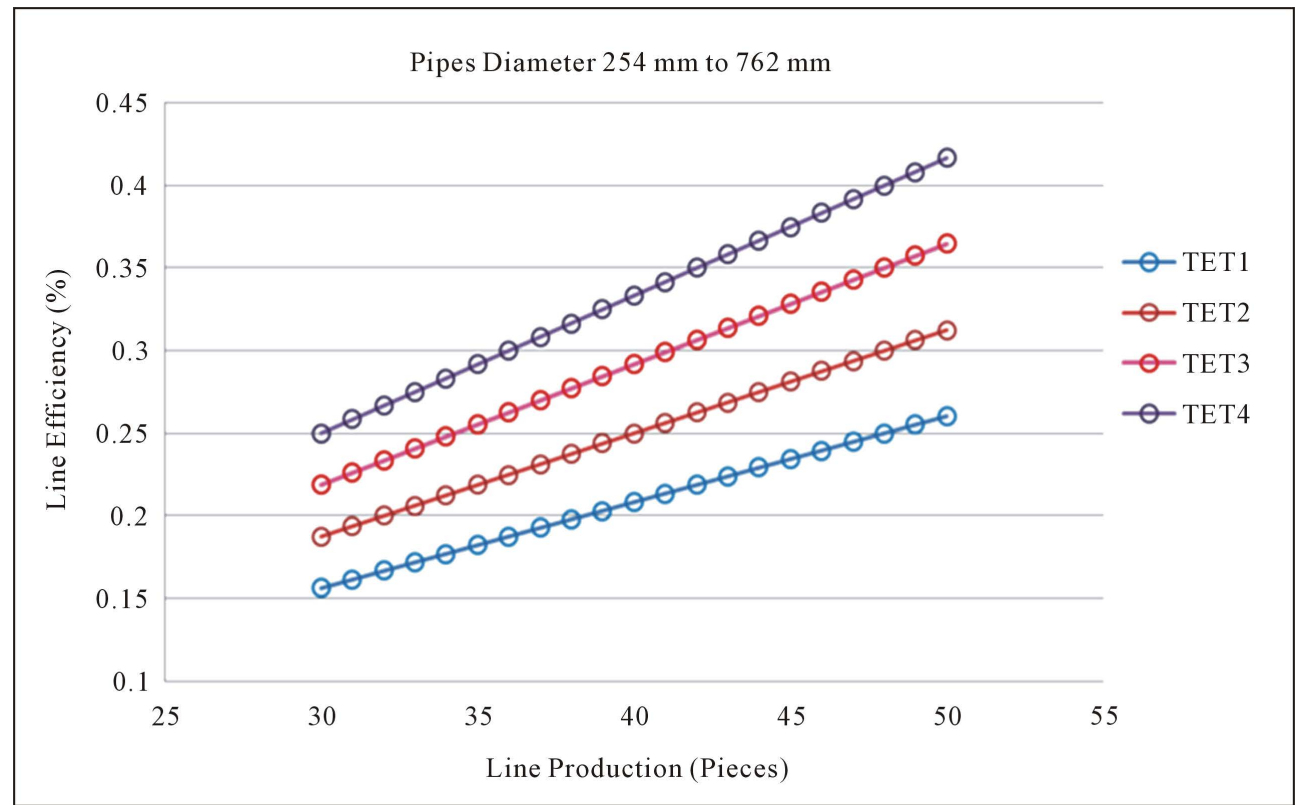

Figure 7. Line efficiency result of microwave station as per the G1, with various long pipe, and NOP $=1$.

The computed results of the maximum LO for each pipe length and shift hours 8, 9, 10, 11 and 12 hrs are shown in Figure 8. It should be noted that we do not consider random events or calibration errors, or necessary repairs to broken testing machinery that occur at work and increase the time interval in the RT station beyond the standard time allowed. For our analysis the recommended velocity of PP processing is assumed to be constant. 


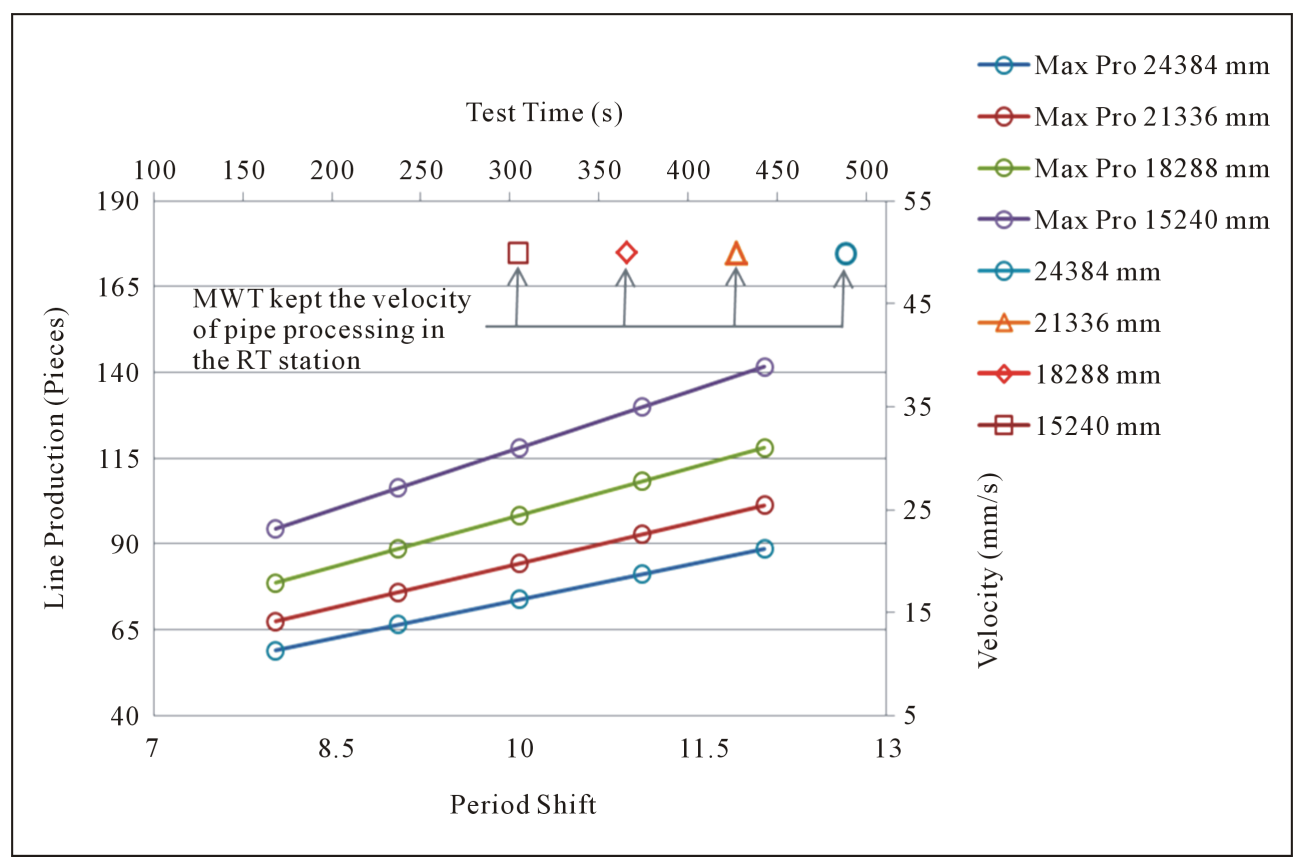

Figure 8. Maximum LO results after microwave station add it to inspect pipes G1, with different length pipe and shift hours.

\subsection{Assess the Ratio of Work Done through Proposed MW Technology}

To evaluate the defects qualitatively and quantitatively using VI for G1, the microwave technique (MWT) was used as the input factor of the LO and LE theoretical analysis, in order to complete the inspection for the defect locations quantitatively. SAM is factored into the proposed method. During the analysis, the exact times to inspect the OD and ID by the inspector were factored into LE calculations. Pipes are inspected in VI and according to the exact time, the ratio of work done was calculated, to be $26.667 \%$ approximately work done by VI for G1. Hence, the rest of the work ratio is $73.334 \%$ approximately done by MWT. Finally, the percentage of work completed by the microwave (MW) station is a high, and this is confirmed in Figure 7 above. MWT kept the velocity of the wagon which carries the pipe during the testing process in the RT station at the recommended velocity according to the standards and codes, as mentioned in [5]. For G2, work done ratios are $100 \%$ for VI and RT individually.

\section{Results and Discussion}

The new generation of line output and efficiency has been managed in view of the complexity of the nondestructive evaluation sequence integrating the latest developments of microwave technology-based inspection systems. MW can be used to control the declining pipe process velocity through the RT station, and to overcome the deficiencies in the aforementioned VI method for G1 pipes.

Figure 4 shows the values of LE for VI station per the characteristics of standardized evaluation of the pipes in this station. The values are divided into two parts, as shown in the graph, partial test and full test according to the diameter groups, G1 \& G2. In G1, the VI has a physical limitation to test the pipes related to pipeline specifications, such as dimension, pipe formation, pipe material and purpose of the pipe. But those inspections must be made because the specifications reflect standard codes. These codes specify to what level pipes are examined in terms of acceptance of sizes of defects (whether a particular size of defect size is acceptable or not) that exist in the body of the pipe or in welded areas. Naturally, the testing standards for oil and gas pipeline vary from, for example a chemical pipeline, during the manufacturing phase. Let us suggest without arguing that the efficiency and production are based on pipe inspection time. And by analyzing the SAM, the LE is controlled by TMP which changes according to the actual time expended to test the pipe. In G2, the pipes are inspected both outside and inside, and thus satisfied the full test. But the LE declines when we compute the LE for G1 which is 
represented only by the partial test. The reason is TMP includes only a partial test for VI which means less time spent to inspect only the outside diameter, the time varies and TMA is constant, as we mentioned above. This is because it depends on the number of operators which is constant for each station according to the requirements, and the length of the work shift is constant according to the production time.

Because of the partial test in the VI station, the RT station must reduce the velocity of the wagon that carries the pipe during the test from $50 \mathrm{~mm} / \mathrm{s}$ to $16.667 \mathrm{~mm} / \mathrm{s}$, as shown in Figure 5 . LO for pipe length 24,384 mm falls from 60 to 18 pieces and from 89 to 27 pieces per shift worked 8 hrs and 12 hrs, respectively. Similarly, Figure 6 shows that reducing the inspection velocity to keep up with quality control requirements causes the LO to decline as shown in Table 1.

\begin{tabular}{cccc}
\hline Table 1. Summary of the reduced velocity per quality control during different shift periods. \\
\hline Pipe Length (mm) & $\begin{array}{c}\text { Maximum Production } \\
\text { (Pieces) }\end{array}$ & $\begin{array}{c}\text { Minimum Production } \\
\text { (Pieces) }\end{array}$ & Period Shift (hr) \\
\hline 24,384 & 89 & 27 & 12 \\
& 60 & 18 & 8 \\
21,336 & 102 & 31 & 12 \\
& 68 & 21 & 8 \\
18,288 & 119 & 36 & 12 \\
& 79 & 24 & 8 \\
15,240 & 142 & 44 & 12 \\
\end{tabular}

Figure 6 and the table show that the shorter the length of the pipe, the more pieces is produced within a shift.

Figure 7 shows the increase in LE as per LO associated with using the microwave station, where improved TET were achieved. More specifically, the curves in Figure 7 demonstrate that the TET's ( $2.5 \mathrm{~min}, 3 \mathrm{~min}, 3.5$ min and $4 \mathrm{~min}$ ) are directly correlated to the length of pipe $(15,240 \mathrm{~mm}, 18,288 \mathrm{~mm}, 21,336 \mathrm{~mm}$ and 24,384 $\mathrm{mm}$ ) respectively.

Finally, Figure 8 shows the measured maximum LO related to the various shift lengths ( 8 hrs, 9 hrs, 10 hrs, 11 hrs and 12 hrs) obtained for four PP lengths as mentioned above. Velocity for the RT wagon improved to 50 $\mathrm{mm} / \mathrm{s}$ for all four PP pipe lengths as shown in Figure 8 with time intervals $487.68 \mathrm{~s}, 426.72 \mathrm{~s}, 365.76 \mathrm{~s}$ and $304.8 \mathrm{~s}$, starting from the longer to shorter PP's. Thus, the final result is that pipe velocity in the RT station was maintained at the recommended velocity for all pipe lengths.

\section{Conclusions}

To analyze the line output and line efficiency of a pipe manufacturing plant at arbitrary and random production capacity due to a partial VI test, we propose to add a microwave station for a particular pipe diameter for the analysis of the PP.

Microwave technology can be situated in diverse production system line configurations in manufacturing plants per the stakeholder and customer needs. In our study, microwave kept the recommended velocity of the RT inspection process synchronized for the PP case, handled a 73.334\% approximately as a ratio of work done for sequence system in the plant, and covered the shortcoming of the VI.

Also MWT kept the pipes at a high level of quality assurance. Because if it is compared to the previous status, before and after using the microwave technique, significant changes may be observed by tracking curves as mentioned above. Even with reduction in velocities of the wagon carrying the pipe out to be examined during the RT station. As mentioned in section 2, it is noted that the inspection is only for the weld areas. Consequently, if there is any defect in the inner wall of the pipe body, it will not be detected. Categorically, the microwave is shown to be a promising technology since it allows the RT station to keep the velocities as recommended. It can detect defects in both the weld and the body of the pipes easily after calibration and without human effort, thus 
preserving the quality of the product is expected to enhance production efficiency for oil and natural gas pipe production.

\section{References}

[1] Okamoto, J., Adamowski, J.C., Tsuzuki, M.S.G., Buiochi, F. and Camerini, C.S. (1999) Autonomous System for Oil Pipelines Inspection. Mechatronics, 9, 731-743. http://dx.doi.org/10.1016/S0957-4158(99)00031-8

[2] Contreras, A., Hernández, S.L., Orozco-Cruz, R. and Galvan-Martínez, R. (2012) Mechanical and Environmental Effects on Stress Corrosion Cracking of Low Carbon Pipeline Steel in a Soil Solution. Materials \& Design, 35, 281-289. http://dx.doi.org/10.1016/j.matdes.2011.09.011

[3] Ju, Y. (2007) Remote Measurement of the Pipe Thickness Reduction by Microwaves. ASME 2007 Pressure Vessels and Piping Division Conference, Texas, 22-26 July 2007, 177-179. http://dx.doi.org/10.1115/pvp2007-26565

[4] Cosham, A. and Hopkins, P. (2004) The Effect of Dents in Pipelines-Guidance in the Pipeline Defect Assessment Manual. International Journal of Pressure Vessels and Piping, 81, 127-139. http://dx.doi.org/10.1016/j.ijpvp.2003.11.004

[5] Alobaidi, W., Sandgren, E. and Al-Rizzo, H. (2015) A Survey on Benchmark Defects Encountered in the Oil Pipe Industries. International Journal of Scientific and Engineering Research, 6, 844-853.

[6] Ahammed, M. and Melchers, R.E. (1996) Reliability Estimation of Pressurised Pipelines Subject to Localised Corrosion Defects. International Journal of Pressure Vessels and Piping, 69, 267-272. http://dx.doi.org/10.1016/0308-0161(96)00009-9

[7] Abbasi, K., Ito, S. and Hashizume, H. (2008) Prove the Ability of Microwave Nondestructive Method Combined with Signal Processing to Determine the Position of a Circumferential Crack in Pipes. International Journal of Applied Electromagnetics and Mechanics, 28, 429-439.

[8] Sarkar, P. (2015) OCS Online Clothing Study. What is the Meaning of SAM in Garment Industry? http://www.onlineclothingstudy.com/2013/12/what-is-meaning-of-sam-in-garment.html

[9] Education Year (2015) Calculate SAM of a Garment. http://educationyears.blogspot.com/2014/05/calculate-sam-of-garment.html

[10] Blue Star, Professional Electronics \& Industrial Systems Division (2015) Material Testing—Non Destructive, Automation Project Capabilities (Ultrasonic Testing System). http://electronics.bluestarindia.com/MatTestNonDest/Auto Proj.htm

[11] Alobaidi, W.M., Alkuam, E.A., Al-Rizzo, H.M. and Sandgren, E. (2015) Applications of Ultrasonic Techniques in Oil and Gas Pipeline Industries: A Review. American Journal of Operations Research, 5, 274-287. http://dx.doi.org/10.4236/ajor.2015.54021

[12] AMERICAN, THE RIGHT WAY (2015) AMERICAN Steel Pipe Manufacturing Process. http://www.american-usa.com/resources/american-steel-pipe-resources/american-steel-pipe-manufacturing-process

[13] YXLON, Technology with Passion (2015) Inspection of Pipe Segments with Longitudinal and Spiral Welds at Pipe Mills. http://www.yxlon.com/Applications/Welds/Pipe-mills

[14] HUNGER, Hydraulik (2015) Hydraulic Equipment for the Mechanical Engineering. http://hunger-hydraulik.de/Mechanical-engineering.html

[15] Deutsch, W., Gessinger, M. and Joswig, M. (2012) ECHOGRAPH Ultrasonic Testing of Helical Submerged ArcWelded (HSAW) Pipes. 18th World Conference on Nondestructive Testing, Durban, 16-20 April 2012, 1-12.

[16] GE Measurement \& Control (2015) Krautkramer USN 60/60L, Portable Ultrasonic Flaw Detectors. http://www.gemeasurement.com/sites/gemc.dev/files/usn_60_60l_brochure.pdf

[17] YXLON, Technology with Passion (2015) Y. Pipe Solutions-X-Ray Systems for Pipe Inspection. http://www.yxlon.com/Products/Pipe-inspection-systems

[18] U. S. Steel Tubular Products (2015) High Frequency Electric Weld (ERW) Line Pipe and Standard Products. http://usstubular.com/standard-and-line-steel-pipe/high-frequency-electric-weld-(erw)-line-pipe-and-s

[19] U.S. Department of Transportation, Pipeline \& Hazardous Materials Safety Administration (2015) Fact Sheet: Pipe Manufacturing Process. https://primis.phmsa.dot.gov/comm/FactSheets/FSPipeManufacturingProcess.htm

[20] Ujam, A.J., Ekere, P.O. and Chime, T.O. (2013) Performance Evaluation of a Gas Turbine Power Plant by the Application of Compressor Off-Line and On-Line Water Washing Techniques. (A Case Study of 450MW Sapele Power Station in Delta State, Nigeria). IOSR Journal of Engineering, 3, 29-41. http://dx.doi.org/10.9790/3021-031112941

[21] Sarkar, P., OCS Online Clothing Study (2015) How to Calculate Efficiency of a Production Batch or Line? http://www.onlineclothingstudy.com/2011/09/4-how-to-calculate-efficiency-of.html 
[22] Song, B.L., Wong, W.K., Fan, J.T. and Chan, S.F. (2006) A Recursive Operator Allocation Approach for Assembly Line-Balancing Optimization Problem with the Consideration of Operator Efficiency. Computers \& Industrial Engineering, 51, 585-608. http://dx.doi.org/10.1016/j.cie.2006.05.002 